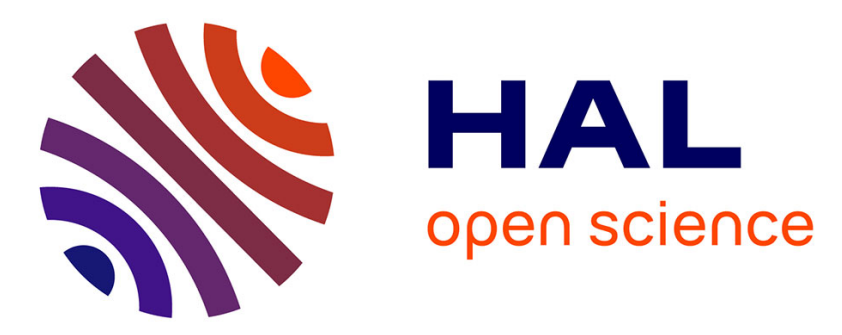

\title{
Mapping of Brain lipid binding protein (Blbp) in the brain of adult zebrafish, co-expression with aromatase B and links with proliferation
}

Nicolas Diotel, Colette Vaillant, Olivier Kah, Elisabeth Pellegrini

\section{- To cite this version:}

Nicolas Diotel, Colette Vaillant, Olivier Kah, Elisabeth Pellegrini. Mapping of Brain lipid binding protein (Blbp) in the brain of adult zebrafish, co-expression with aromatase B and links with proliferation. Gene Expression Patterns, 2016, 20 (1), pp.42-54. 10.1016/j.gep.2015.11.003 . hal-01237088

HAL Id: hal-01237088

https://hal-univ-rennes1.archives-ouvertes.fr/hal-01237088

Submitted on 6 Feb 2018

HAL is a multi-disciplinary open access archive for the deposit and dissemination of scientific research documents, whether they are published or not. The documents may come from teaching and research institutions in France or abroad, or from public or private research centers.
L'archive ouverte pluridisciplinaire HAL, est destinée au dépôt et à la diffusion de documents scientifiques de niveau recherche, publiés ou non, émanant des établissements d'enseignement et de recherche français ou étrangers, des laboratoires publics ou privés. 


\title{
Mapping of brain lipid binding protein (Blbp) in the brain of adult zebrafish, co-expression with aromatase B and links with proliferation
}

\author{
Nicolas Diotel ${ }^{\text {a, b, c, * }}$, Colette Vaillant ${ }^{c}$, Olivier Kah ${ }^{\text {c }}$, Elisabeth Pellegrini ${ }^{c}$ \\ a Inserm, UMR 1188 Diabète athérothrombose Thérapies Réunion Océan Indien (DéTROI), plateforme CYROI, Sainte-Clotilde, F-97490, France \\ ${ }^{\mathrm{b}}$ Université de La Réunion, UMR 1188, Sainte-Clotilde, F-97490, France \\ 'Inserm U1085, Université de Rennes 1, Campus de Beaulieu, Research Institute in Health, Environment and Occupation, SFR Biosit, Rennes cedex, France
}

\section{A B S T R A C T}

Adult fish exhibit a strong neurogenic capacity due to the persistence of radial glial cells. In zebrafish, radial glial cells display well-established markers such as the estrogen-synthesizing enzyme (AroB) and the brain lipid binding protein (Blbp), which is known to strongly bind omega-3 polyunsaturated fatty acids such as docosahexaenoic acid (DHA). While Blpb is mainly described in the telencephalon of adult zebrafish, its expression in the remaining regions of the brain is poorly documented. The present study was designed to further investigate Blbp expression in the brain, its co-expression with AroB, and its link with radial glial cells proliferation in zebrafish. We generated a complete and detailed mapping of Blbp expression in the whole brain and show its complete co-expression with AroB, except in some tectal and hypothalamic regions. By performing PCNA and Blbp immunohisto-chemistry on cyp19a1b-GFP (AroB-GFP) fish, we also demonstrated preferential Blbp expression in proliferative radial glial cells in almost all regions studied. To our knowledge, this is the first complete and detailed mapping of Blbp-expressing cells showing strong association between Blbp and radial glial cell proliferation in the adult brain of fish. Given that zebrafish is now recognized models for studying neurogenesis and brain repair, our data provide detailed characterization of Blbp in the entire brain and open up a broad field of research investigating the role of omega-3 polyunsaturated fatty acids in neural stem cell activity in fish.

\section{Introduction}

Brain lipid binding protein (Blbp) is a fatty acid binding protein but its exact functions are poorly understood. It is believed to play a key role in lipid storage, membrane synthesis, energy production via lipid transport to the mitochondria, cholesterol metabolism and cell signaling. Its role in cell signaling is thought to involve pairing of fatty acids and transcription factors, such as members of the peroxisome proliferator-activated receptor family (PPAR) (Krelin et al., 2007). During brain development in rats, Blbp is detected in the nucleus and cytoplasm of radial glia in both the embryonic ventricular zone and in Bergmann glia of the postnatal cerebellum. Its expression correlates with neuronal differentiation notably in the postnatal cerebellum, the embryonic spinal cord, and the cerebral cortex (Feng et al., 1994). In adult mice, Blbp is also expressed in radial glia-like cells in the dentate gyrus of the hippocampus, in Bergman glia in the cerebellum (Kurtz et al., 1994) and in almost all astrocytes or astrocyte-like cells of the subventricular zone (Hartfuss et al., 2001). Similarly, in adult bird brains, Blbp is detected in telencephalic and cerebellar radial glial cells as well as in astrocytes ( Rousselot et al., 1997). Binding affinity assays strongly suggested that in the central nervous system, docosahexaenoic acid (DHA; 22:6 ( $\omega-3)$ ) is the ligand for Blbp in the central nervous system (Xu et al., 1996). DHA is the most abundant omega-3 polyunsaturated fatty acids and is essential for appropriate retinal and neural development. Moreover, several studies suggest that DHA has protective role in the brain against age-related disorders and neurodegenerative diseases such as Alzheimer's (Cole et al., 2010; Crawford et al., 2013; Hoffman et al., 2009). DHA can be locally metabolized in the organism to generate newly described

\footnotetext{
* Corresponding author. Inserm U1188, Université de La Réunion, Equipe DéTROI Plateforme CYROI, 2 rue Maxime Rivière, 97 490, Sainte-Clotilde, France. E-mail address: nicolas.diotel@univ-reunion.fr (N. Diotel).
} 
lipids such as resolvins and neuroprotectins, autacoids with potential anti-inflammatory properties, (Gronert, 2008). Knock-out (KO) experiments have shown that Blbp disrupted mice display emotional and behavioral disturbances, including anxiety (Owada et al., 2006). In their work, Owada et al. (2006) did not observe any abnormality at the level of tissue organization and glial morphology in the cerebral and cerebellar cortex, the hippocampus or the hypothalamus in embryonic and mature KO animals. However, more recent data indicate that Blbp and DHA are involved in neurogenic processes, such as neural stem cell maintenance, proliferation and differentiation (Boneva et al., 2011; Matsumata et al., 2012; Schnell et al., 2014; Watanabe et al., 2007), suggesting that DHA and Blbp are indeed important factors for brain development and neurogenesis.

Adult neurogenesis is a complex and multistep process regulated by intrinsic and extrinsic factors (Hsieh, 2012). Among these factors, hormones, notably estrogens, exert pleiotropic actions to modulate several aspects of neurogenesis such as proliferation, neuronal differentiation and survival (Brock et al., 2010; Diotel et al., 2013; Galea et al., 2006, 2008; Garcia-Segura, 2008). These estrogens are obtained through the conversion of C19 androgens by the enzyme cytochrome P450 aromatase (aromatase). Aromatase is expressed by numerous tissues, including gonads and brain of all vertebrates species studied so far (Simpson et al., 1994). Very interestingly, in contrast to mammals, the brains of adult fish exhibit an exceptionally strong neurogenic and aromatase activity in different regions such as the telencephalon, the preoptic area and also the hypothalamus (Diotel et al., 2010a; Goncalves et al., 2008; Kah et al., 2009; Pasmanik and Callard, 1985; Pellegrini et al., 2013; Timmers et al., 1987), suggesting the strong link between estrogen synthesis and neurogenesis (Diotel et al., 2013). The high level of aromatase activity in the fish brain is driven by the intense transcription of the cyp19a1b gene coding for aromatase B (AroB) (Diotel et al., 2010a; Lassiter and Linney, 2007; Mouriec et al., 2009; Pellegrini et al., 2015, 2005; Tong et al., 2009). While in mammals aromatase expression is mainly observed in neurons and in reactive astrocytes following injury (Garcia-Segura, 2008; Garcia-Segura et al., 1999), AroB in fish is expressed only in radial glia, specific cells that behaves as neural stem cells (Diotel et al., 2010a; Forlano et al., 2001; Mouriec et al., 2008; Pellegrini et al., 2005, 2007, 2013; Tong et al., 2009). Radial glial cells have been relatively wellcharacterized in the fish brain and particularly in the telencephalon. First, radial glial cells are localized in the ventricular layers and exhibit a typical morphology characterized by a small cell body localized in the ventricular layers, with one short process extending towards the ventricle and a long process crossing the brain parenchyma to contact the pial surface with end feet, similar to mammals (Bentivoglio and Mazzarello, 1999; Rakic, 1978). Second, a number of immunohistochemical markers have confirmed the identity of radial glial cells in zebrafish. Among these are Blbp (brain lipid binding protein), gfap (glial fibrillary acidic protein), $\mathrm{S} 100 \beta$ (S100 calcium binding protein B), cxcr4 (C-X-C chemokine receptor type 4), id1 (inhibitor of DNA binding 1 , a transcription regulator) and also the estrogen-synthesizing enzyme, aromatase $B$ (AroB), encoded by the cyp19a1b gene(Dinarello, 2012; Diotel et al., 2010b; Diotel et al., 2015; März et al., 2010; Menuet et al., 2005; Rodriguez Viales et al., 2015; Tong et al., 2009). Although some studies reported the expression of Blbp in radial glial cells in the brain of adult zebrafish (Adolf et al., 2006; Edelmann et al., 2013; März et al., 2010), they mainly focus on Blbp expression in the telencephalon, leaving other brain regions relatively unexplored (Adolf et al., 2006; Edelmann et al., 2013; März et al., 2010).

Numerous genes were duplicated in teleost fish following the genomic duplication that occurred between 320 and 350 million years ago (Glasauer and Neuhauss, 2014; Steinke et al., 2006).
Among those, Blbp gene was also duplicated into fabp7 $a$ and $b$ in zebrafish. Fabp7a is strongly expressed in the brain of adult zebrafish as shown by RT-PCR experiments (Liu et al., 2004, 2003). In situ hybridization experiments further showed that fapb7a is strongly expressed in the telencephalic ventricular zone and in the periglomerular grey zone of the optic tectum (Adolf et al., 2006; Ito et al., 2010). Thus, the fabp7a isoform appears to be the main gene transcribed in the adult zebrafish brain.

Blbp expression was also described in glial cells from adult zebrafish cerebellum (Kaslin et al., 2009). However, given the real lack of data concerning Blbp expression in the whole brain of adult zebrafish, we first investigated the detailed distribution of Blbppositive cells in the entire adult brain using an already characterized antibody. Next, we compared Blbp expression with AroB one, a well-recognized marker of radial glial cells in fish, using a cyp19a1b-GFP transgenic zebrafish line that fully recapitulates AroB protein expression in the brain (Tong et al., 2009). Finally, given the high number of neurogenic hotspots described in the brain of adult zebrafish, we examined if radial glial cell proliferation was preferentially associated with Blbp expression and/or with AroB.

\section{Results}

\subsection{Blbp is expressed in radial glia in the whole brain}

Blbp was previously shown to label radial glial cells in adult zebrafish and larvae (Adolf et al., 2006; Diotel et al., 2010b; März et al., 2010; Tong et al., 2009). To complete the pattern of Blbp expression previously described in the adult telencephalon, we decided to further document its expression by performing immunohistochemistry in the whole brain of adult male and female zebrafish (Figs. 1-4). Our analysis of Blbp expression in the brain of adult zebrafish will be described according to the rostro-caudal axis, from the olfactory bulbs/telencephalon junction, to the telencephalon, the diencephalon, the mes- and metencephalon.

At the junction between the olfactory bulbs and the telencephalon, Blbp-positive cells were observed in the ventricular layer (Figs. 1A, 2B and 4A), and extend processes toward the pial surface (Fig. $1 \mathrm{~A}, \mathrm{D}, \mathrm{F}$ and $\mathrm{H}$, see arrows).

In the telencephalon, Blbp-expressing radial glial cells were detected along the ventricular layer of the ventral and dorsal nuclei of the ventral telencephalon ( $\mathrm{Vv}$ and Vd, Figs. 1B, 2E and 4B), the ventricle of the dorsomedian and dorsolateral telencephalon (Dm and $\mathrm{Dl}$, Figs. $1 \mathrm{~B}-\mathrm{D}, 2 \mathrm{H}$ and $4 \mathrm{~B}$ and $\mathrm{C}$ ), as well as in the ventricular layer of the dorsal and posterior zone of the dorsal telencephalic area (Dd and Dp, Figs, 1B, D and 4C). We also noticed a ventricular strip devoid of Blbp staining, at the junction between the $\mathrm{Vv}$ and the Vd (Fig. 1B, asterisks). A lack of Blbp expression was previously documented in this region corresponding to a highly proliferative area called the rostral migratory stream (RMS). This regions is devoid of radial glial cells but contains committed progenitors called neuroblasts (März et al., 2010). More caudally in the telencephalon, ventricular cells in the postcommissural nucleus of the ventricular telencephalic area (Vp) also express Blbp (Figs. 1D and 4C).

In the anterior part of the diencephalon, Blbp expression was detected in radial glial cells of the anterior ( $\mathrm{PPa}$ ) and posterior (PPp) nuclei of the preoptic area (Figs. 1D, E, 4C and D) and in the thalamus (A, Fig. 4E). In the anterior, mediobasal and caudal part of the hypothalamus (Hv and $\mathrm{Hc}$ ) (Figs. $1 \mathrm{~F}, \mathrm{H}, 2 \mathrm{~N}, 3 \mathrm{E}, \mathrm{H}$ and $4 \mathrm{E}-\mathrm{G}$ ), numerous Blbp-positive radial glial cells were detected and extend long cytoplasmic processes to the periphery of the brain where they accumulate at the pial surface (Fig. $1 \mathrm{~F}$ and $\mathrm{H}$, see arrows). In the dorsal zone of the periventricular hypothalamus, radial glial cells surrounding the lateral and posterior recess (LR and PR) of the caudal hypothalamus exhibit strong Blbp staining (Figs. 1H, 3E and H). 


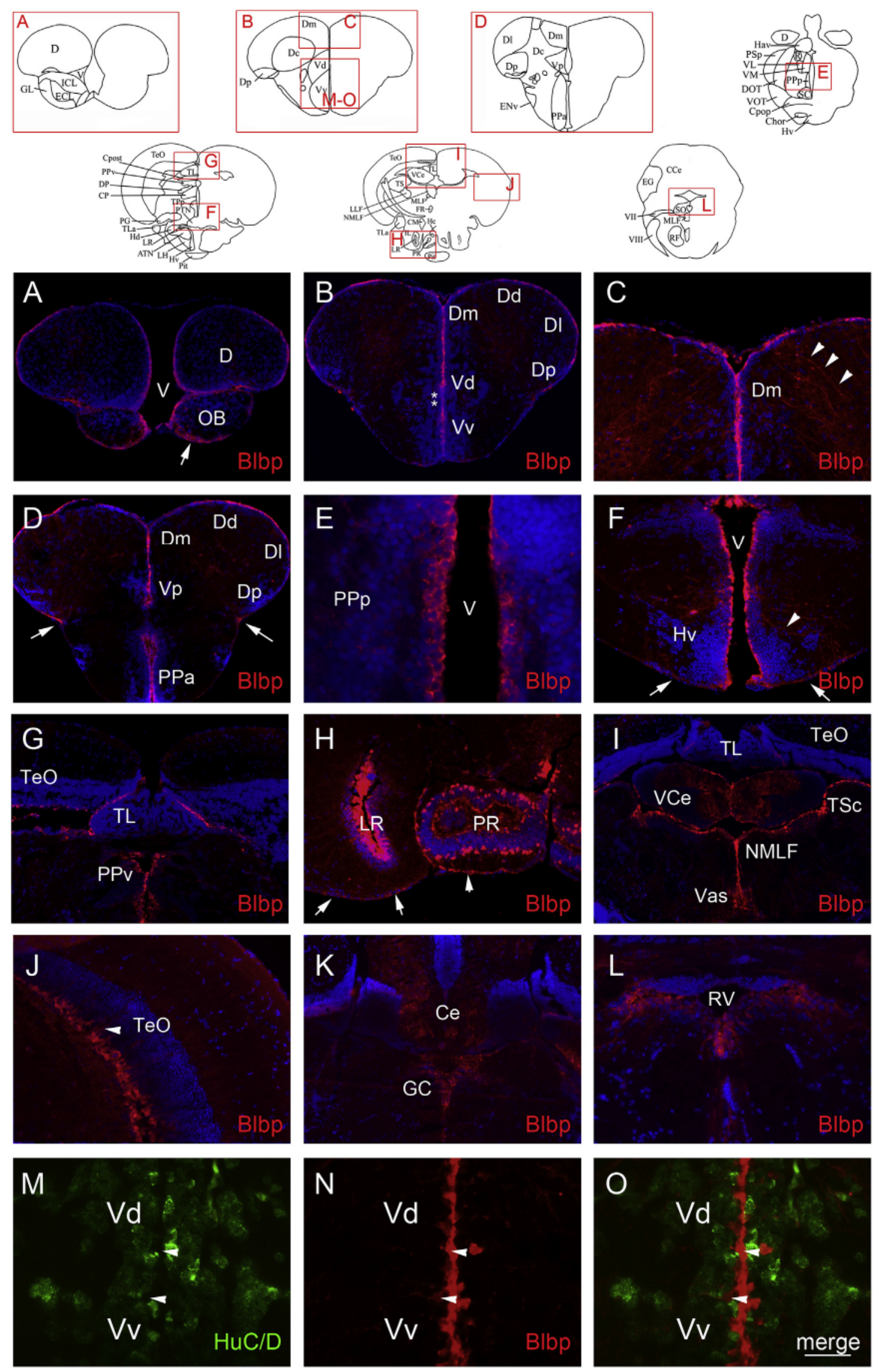


In the mesencephalon, ventricular cells of the periventricular pretectal nucleus (PPv) and of the periglomerular gray zone of the optictectum ( $\mathrm{TeO}$ ) also display Blbp staining (Fig. 1G, I, J, 3K and 4F-H. In the $\mathrm{TeO}$, radial glial processes are clearly visible at higher magnification (Fig. 1J, see arrowhead). Blbp labeling was also detected at the periphery of the torus longitudinalis (TL, Fig. 1G and I).

In the metencephalon, blbp staining was also observed at the periphery of the valvula cerebelli (VCe) and more weakly in the cerebellum (CCe) (Fig. 1I, K, 3K and 4G-I). It is also observed at the border of the torus semi-circularis and numerous fibers were detected through the nucleus of the medial longitudinal fascicle (NMLF), extending along the vascular lacuna of area postrema (Vas) as shown in Fig. 1I. More caudally, Blbp was detected in cells surrounding the rhombencephalic ventricle (RV) until the end of the medulla oblongata (Fig. $1 \mathrm{~K}$ and L). In all these regions, Blbp was not co-expressed with the nuclear neuronal marker HuC/D such as shown in the subpallium (Fig. $1 \mathrm{M}-\mathrm{O}$ ). We also did not observe any obvious differences in Blbp distribution according to sex.

\subsection{Blbp and cyp19a1b-GFP expression in radial glial cells: co- expression and heterogeneity}

As previously mentioned, Aromatase B, the product of the cyp19a1b gene, is a well-characterized marker of radial glia in the brain of zebrafish. In order to study the co-expression of Blbp and AroB in radial glia, we performed Blbp immunohistochemistry on a cyp19a1b-GFP transgenic zebrafish line (Figs. 2-4). This transgenic line was previously shown to fully recapitulate AroB expression (Tong et al., 2009). We observed the co-expression of Blbp with cyp19a1b-GFP positive radial glia in the main ventricular regions of the brain (Figs. 2 and 4). For instance, in the anterior part of the brain, Blbp and cyp19a1b-GFP were co-expressed in radial glial cells of the dorsal telencephalic area (D) at the junction between the olfactory bulbs and the telencephalon (Fig. $2 \mathrm{~A}-\mathrm{C}$ and $4 \mathrm{~A})$. Such a co-expression was also observed in the whole telencephalon, notably in the Vv, Vd, Dm and Dl (Fig. 2D-I and 4B and C). In the diencephalon, we noticed that radial glia co-express both cyp19a1b-GFP and Blbp in the preoptic area (Fig. 4C and F), in the periventricular nucleus of the posterior tuberculum (TPp, Fig. 2J-L and $4 \mathrm{E}$ and F) and also in the anterior part of the hypothalamus (Fig. 2M-O and 4E). Interestingly, radial glial cells of the PPv strongly displayed Blbp staining while cyp19a1b-GFP is not or only barely expressed by few cells (Fig. $3 \mathrm{~A}-\mathrm{C}$ - see arrows - and Fig. 4F). In the dorsal zone of the mediobasal hypothalamus, where the lateral recess (LR) starts to open, dichotomy also appeared between Blbp and cyp19a1b-GFP expression (Fig. 3D-F). At this level, only a few cells were GFP-positive while numerous Blbpexpressing radial glial cells were observed surrounding the ventricle (Fig. 3D-F, see arrows). Some cells were double labeled (Fig. 3D-F, see arrowheads). However, the strength of these regional differences depends on the rostro-caudal level (Fig. 4F). Such discrepancies in protein expression were also detected more caudally where the LR is well individualized and visualized
(Fig. 3G-I). Thus, among radial glia lining the external part of the LR, we observed a higher number of Blbp-positive cells compared to GFP-expressing cells (Fig. 3G-I - see arrows - and Fig. 4G). In contrast, radial glial cells lining the inner part of the LR mainly coexpressed both markers (Fig. 3G-I, see arrowheads). Differences were also noticed in radial glia of the periglomerular gray zone of the optic tectum where radial glial cells were more numerous and displayed a stronger staining for Blbp than for cyp19a1b-GFP. Similarly, we detected Blbp-positive structures in the NMLF and the valvula of the cerebellum while no GFP was observed (Fig. 3J-L and Fig. 4G and $\mathrm{H}$ ).

\subsection{Radial glia proliferation: is there a preferential link with blbp and/or AroB expression?}

In order to determine possible or preferential association between Blbp and/or AroB expression in proliferative radial glial cells, we performed PCNA and Blbp immunohistochemistry on cyp 19a1b-GFP transgenic line and focused on different neurogenic regions of the brain (Fig. 5, Table 1). In order to avoid potential differences associated to sex and ages, we only used 6 females of the same age. As illustrated in Fig. 5, we observed proliferative cells in the dorsomedian telencephalon that are Blbp-positive only (Fig. 5, A1 and B1), cyp19a1b-GFP-positive only (Fig. 5, A2 and B2), cyp19a1b-GFP and Blbp-positive (Fig. 5, A3 and B3) and others that were neither cyp19a1b-GFP nor Blbp-positive (Fig. 5A, A4 and B4). This latest cell type is not radial glia but correspond to further committed precursors as previously described (März et al., 2010). Interestingly, there was a significantly higher proportion of PCNA-positive radial glial cells that co-expressed both markers in all the regions studied ( $54.9 \%$ for PPp, $55.4 \%$ for Hd LR, $55.6 \%$ for $\mathrm{Dl}, 61.2 \%$ for $\mathrm{Vd}, 66.6 \%$ for $\mathrm{Vv}, 68.6 \%$ for $\mathrm{Dm}, \mathbf{7 9 . 9 \%}$ for $\mathrm{Vs}, \mathbf{8 1 . 8 \%}$ for $\mathrm{PPa}, \mathbf{8 5 . 4 \%}$ for Vp, see Fig. 5C and D and Table 1), except in the thalamus and the PPv where respectively $75.1 \%$ and $90.4 \%$ of proliferative radial glial cells expressed only Blbp. Thus, in all brain areas studied except for the dorsal regions of the periventricular hypothalamus (Hd LR, Fig. 5G and Table 1), the remaining proliferative cells that do not co-express both markers were mainly Blbp-positive while only few cells displayed only cyp $19 a 1 b$-GFP staining ( $1.2 \%$ for Vv, $0.7 \%$ for Vd, $1.4 \%-5.3 \%$ for PPa, $0 \%$ for Vs, $5.8 \%$ for $\mathrm{Vp}, 1.7 \%$ for $\mathrm{Dm}, \mathbf{0 . 9 2} \%$ for $\mathrm{Dl}, 14.3 \%$ for PPp). Indeed, there are significantly more PCNA-positive radial glia expressing only Blbp, except for in the PPa, PPp and the Vp (Fig. 5 and Table 1).

Indeed, $75.1 \%$ and $90.4 \%$ of PCNA-positive radial glial cells expressed only Blbp in the thalamus and PPv respectively, while the remaining cells mainly co-expressed Blbp and cyp19a1b-GFP. Only rare proliferative radial glial cells express only cyp19a1b-GFP (Fig. $5 \mathrm{E}$ and $\mathrm{F}$ and Table 1 ). In contrast, in the Hd LR where the lateral recesses start to open, the distribution of Blbp and cyp19a1b-GFP in proliferative radial glia is changed. Around $55 \%$ of PCNA-positive radial glial cells co-expressed cyp19a1b-GFP and Blbp, followed by $34 \%$ that only express cyp19a1b-GFP and $10 \%$

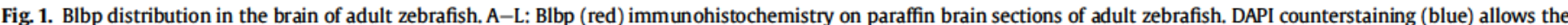

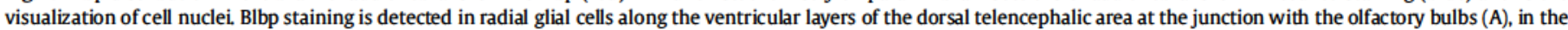

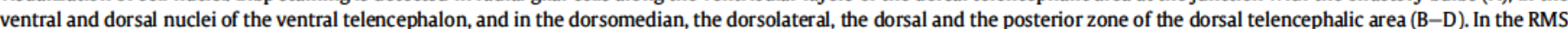

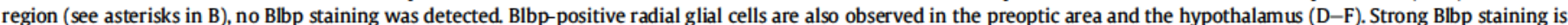

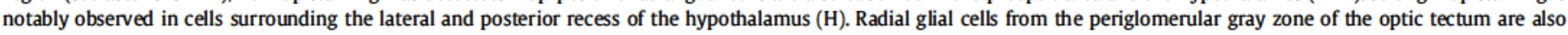

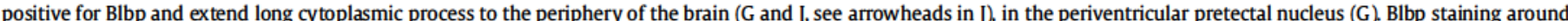

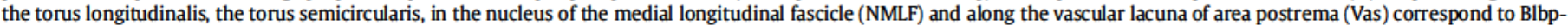

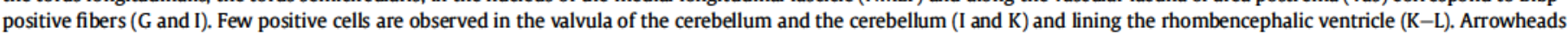

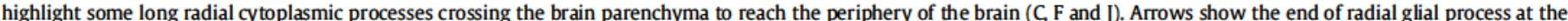

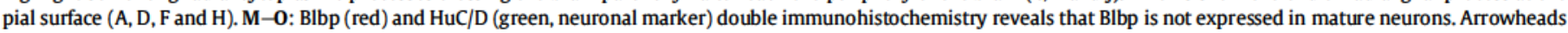
indicate Blbp positive radial glial cells that do not express the HuC/D neuronal marker. Bar: $16 \mu \mathrm{m}(\mathrm{E}, \mathrm{J}, \mathrm{M}, \mathrm{N}$ and 0 ); $50 \mu \mathrm{m}(\mathrm{C}, \mathrm{F}, \mathrm{G}$ and $\mathrm{L}$ ); $100 \mu \mathrm{m}(\mathrm{A}, \mathrm{B}, \mathrm{D}, \mathrm{H}, \mathrm{I}$ and $\mathrm{K})$. 

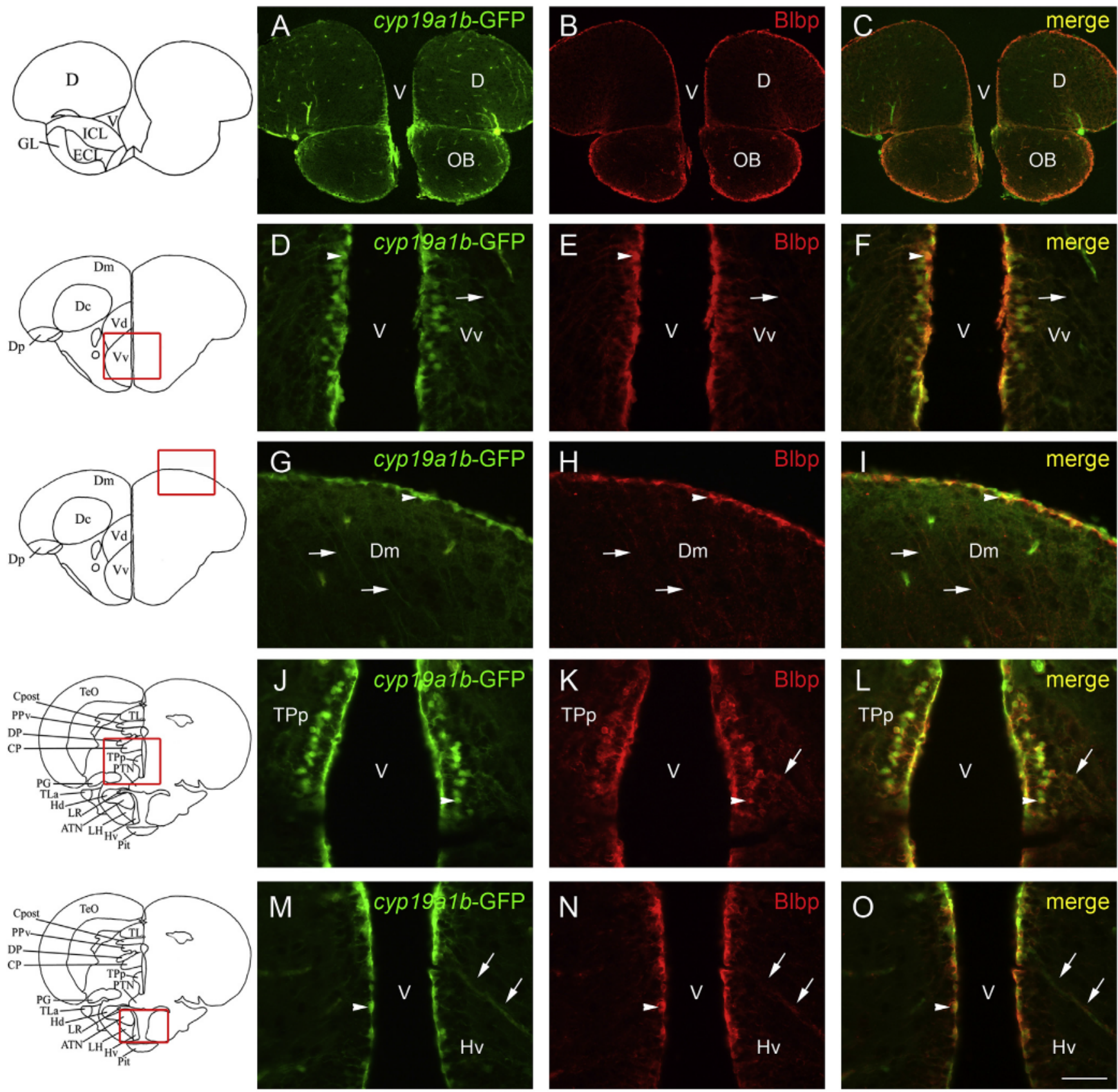

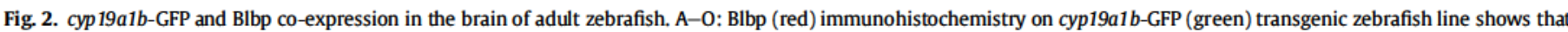

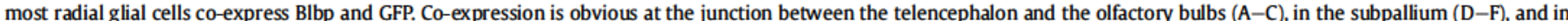

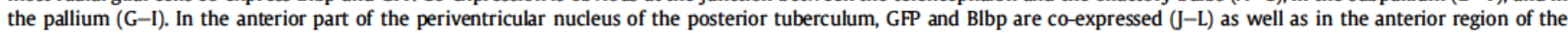

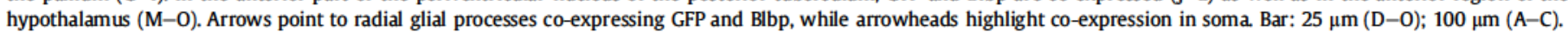

only stained for Blbp (Fig. 5G). This region is the only one to show a significantly higher number of proliferative radial glia expressing at least cyp19a1b-GFP compared to Blbp alone (Table 1).

Taken together, these data show that proliferative radial glial cells express at least Blbp in all the neurogenic regions studied (except Hd LR) and that proliferation is strongly and significantly associated with this marker. Indeed, in the Dl, Dm, Vd, Vv and Vs proliferative radial glial cells expressed at least Blbp (99.1\% for Dl; $98.3 \%$ for Dm; $99.3 \%$ for Vd; $98.8 \%$ for Vv and $100 \%$ for Vs), while only $56.5 \%-79.9 \%$ expressed at least AroB (56.5\% for $\mathrm{Dl}$; $70.3 \%$ for $\mathrm{Dm}$; $61.9 \%$ for $\mathrm{Vd}$; $67.8 \%$ for $\mathrm{Vv}$ and $79.9 \%$ for Vs), that is significantly different (Table 1). The large difference in the thalamus and the PPv are likely due to the low number of cyp19a1b-GFP radial glia compared to Blbp-positive cells (Fig. 5E and $\mathrm{F}$ and Table 1). Interestingly, we observed more proliferative radial glial cells around the LR expressing cyp19a1b-GFP than Blbp (89.9\% Vs 65.5\%, respectively). To conclude, in most cerebral regions studied (Vv, Vd, PPa, Vs, Vp, Dm, Dl, PPp, Hd LR) proliferative radial glia mainly co-expressed cyp19a1b-GFP/Blbp. 

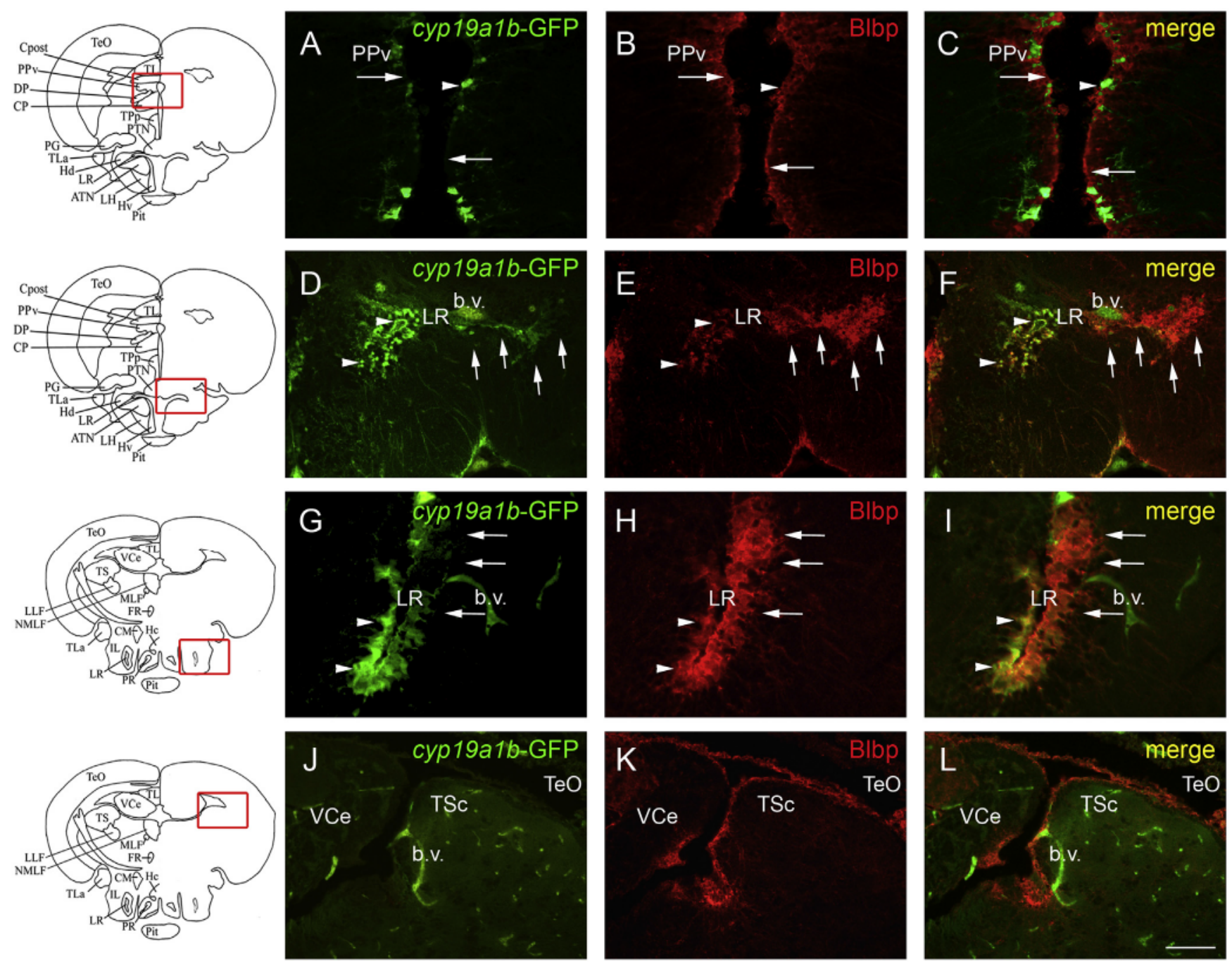

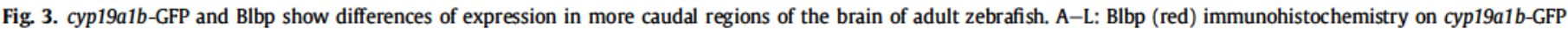

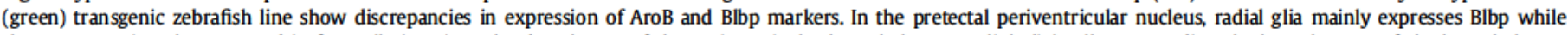

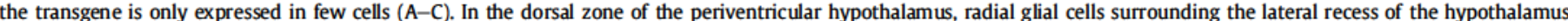

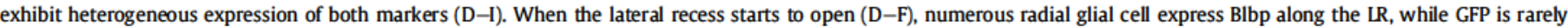

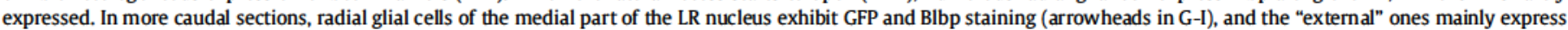

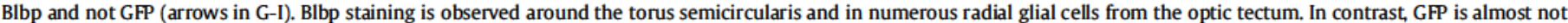
detected (J-L). Bar: $25 \mu \mathrm{m}(\mathrm{G}-\mathrm{I}) ; 50 \mu \mathrm{m}$ (A-F and J-L).

In some regions, dividing glial cells expressed Blbp only and more rarely, radial glial dividing cells expressed solely cyp19a1bGFP.

\section{Discussion}

\subsection{Blbp is widely expressed in radial glial cells acting as neural progenitors}

This study is the first to generate a detailed and complete mapping of Blbp expression in radial glial cells of the adult zebrafish brain, adding significantly to previous work (Adolf et al., 2006; März et al., 2010; Tong et al., 2009). The identity of Blbp-expressing cells was confirmed (1) by cell morphology and reinforced (2) by co-expression with AroB, a well characterized marker of radial glia in zebrafish, using a cyp19a1b-GFP line (Figs. 2-4) and also (3) by the absence of co-expression with the HuC/D neuronal marker (Fig. $1 \mathrm{M}-\mathrm{O}$ ). However, given the two Blbp isoforms in fish, we cannot exclude fabp 7b protein detection by immunohistochemistry due to cross-reaction of the antibody between fabp7a and fabp7b. Briefly, Blbp-positive radial glial cells were detected in the telencephalon (subpallium and pallium), the diencephalon, and in the mes- and metencephalon. The expression of Blbp in radial glial cells, acting as neural progenitors, is in line with to what has previously been described in rodents and humans during the development and the neonatal period (Anthony et al., 2005; Hartfuss et al., 2001; Hebsgaard et al., 2009; Kurtz et al., 1994; Li et al., 2011; Murrell et al., 2005; Podgornyi and Aleksandrova, 2009), and in the brain of adult mammals (Hebsgaard et al., 2009; Marko et al., 2011; Steiner et al., 2006; Takahashi and Yamanaka, 2006), birds (Rousselot et al., 1997) and amphibians (D'Amico et al., 2011). In the hippocampus of adult monkeys, Blbp is expressed in neural progenitors but not in newly generated neurons expressing PSANCAM (polysialylated neuronal cell adhesion molecule) (Boneva et al., 2011). Similarly, in the RMS of zebrafish, neuroblasts express PSA-NCAM but not radial glial markers (März et al., 2010). 

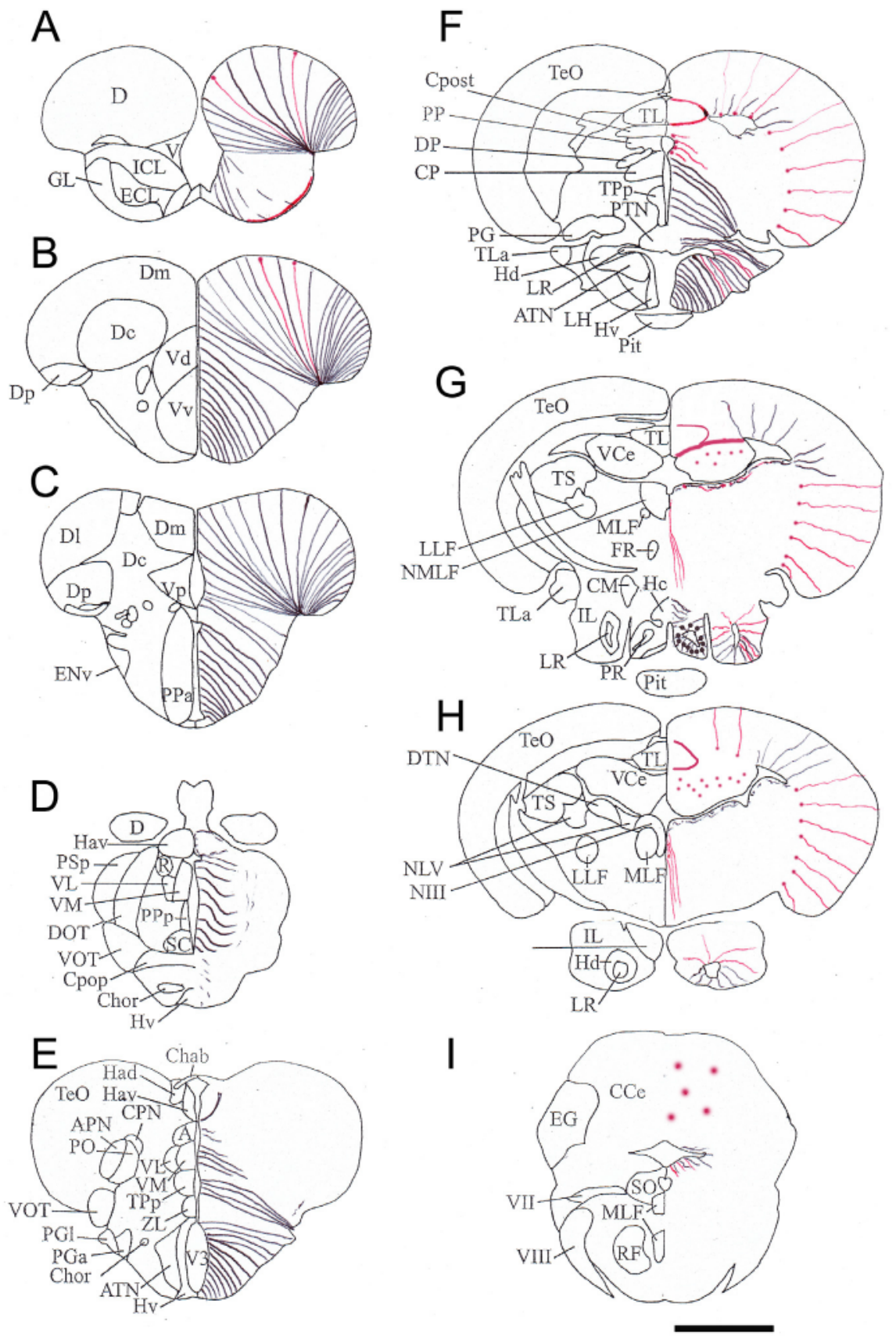

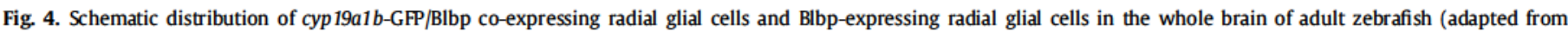

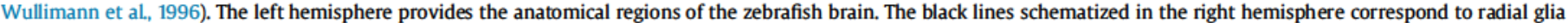

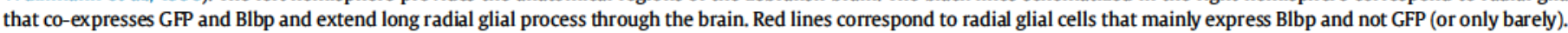

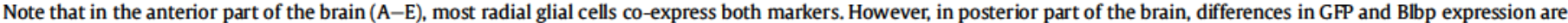

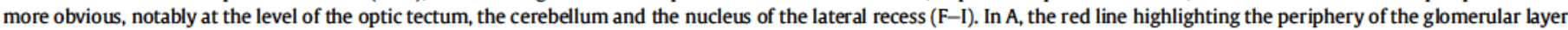
(GL) of the olfactory bulbs corresponds to a strong labeling of end feet at the pial surface. Bar: $350 \mu \mathrm{m}$.

Thus, Blbp expression appears to be mostly associated to radial glia and less to committed precursors (neuroblasts) in mammals and fish.

We also reported Blbp expression in the periglomerular grey zone of the optic tectum as previously shown for fabp7a (Ito et al., 2010). We observed weak Blbp staining in the cerebellum, probably in Bergmann glia, a specific type of radial glia shown to express Blbp in mammals and birds and more recently in zebrafish (Boneva et al., 2011; Feng et al., 1994; Feng and Heintz, 1995; Kaslin et al., 2009; Kurtz et al., 1994; Rousselot et al., 1997). Interestingly, two different populations of glial cells were previously reported in adult zebrafish cerebellum, including one with radial glia phenotype (Kaslin et al., 2009). Taken together, these data show that Blbp expression in radial glia is evolutionarily conserved and suggest key roles for Blbp, DHA and possibly lipid-derived autacoids in brain development stem cell activity.

\subsection{Radial glial cells are not a homogeneous population}

In this work, we also observed that the distribution of Blbp- 

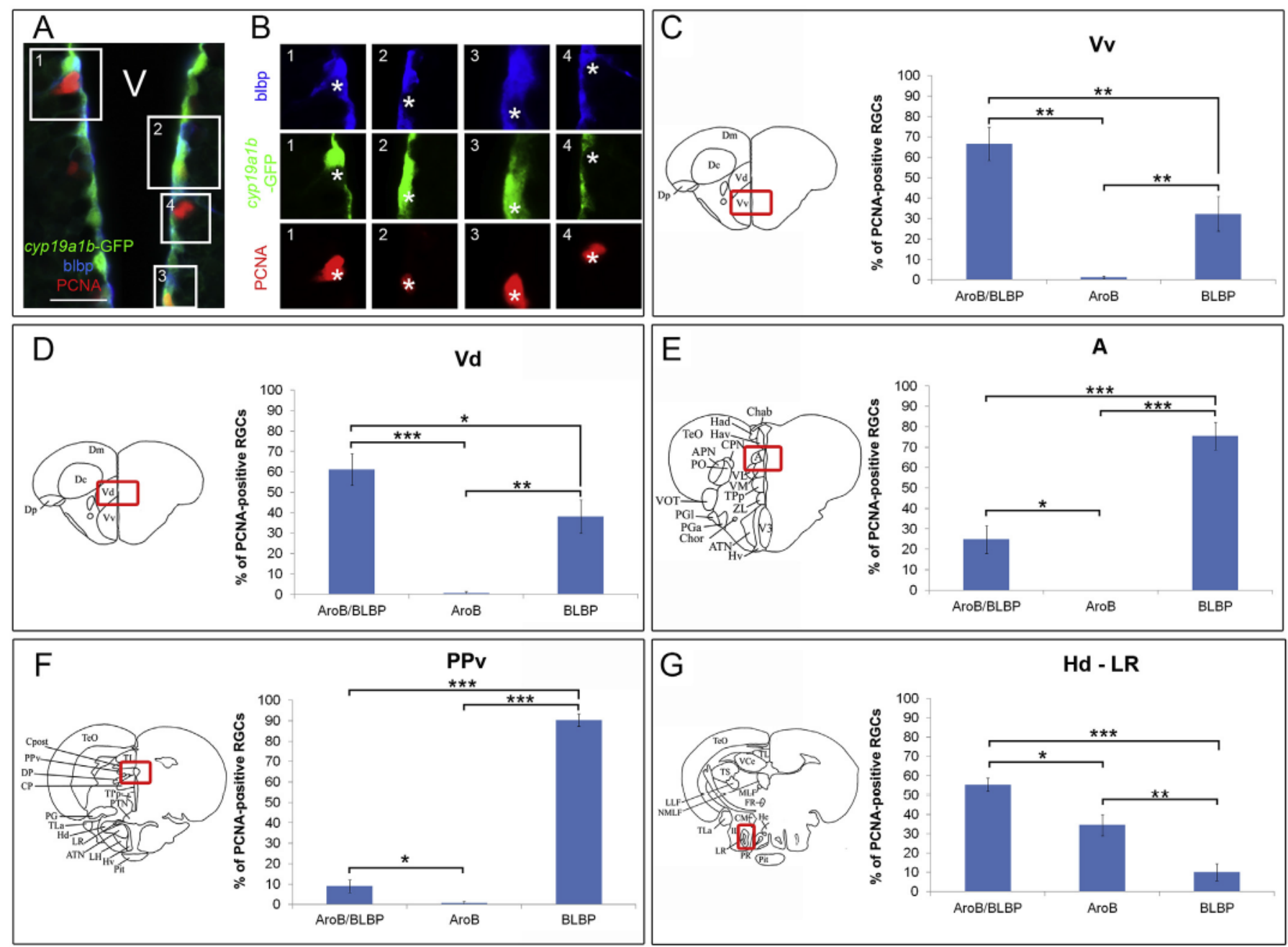

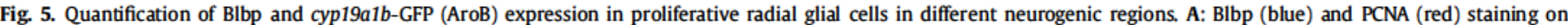

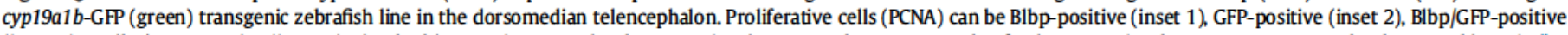

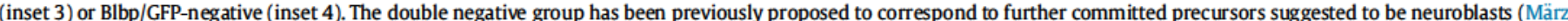

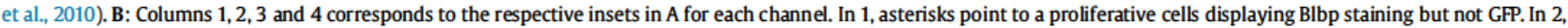

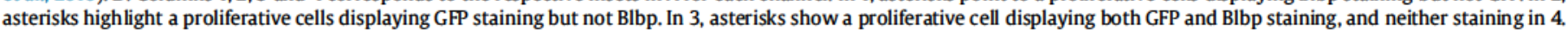

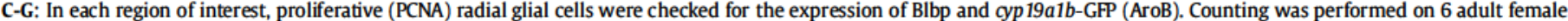

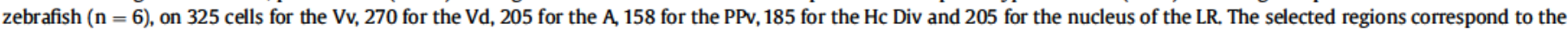

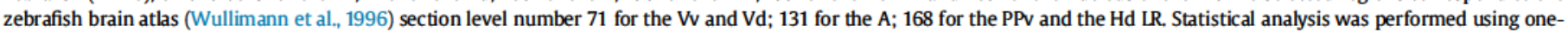
way ANOVA. Error bars correspond to standard errors ( $\mathrm{n}=6$ zebrafish). ${ }^{*} 0,01<\mathrm{p}<0,05 ;{ }^{* *} 0,01<\mathrm{p}<0,0001 ;{ }^{* * *} \mathrm{p}<0,0001$.

positive and Aro-B expressing (or cyp19a1b-GFP) radial glial cells is similar (Menuet et al., 2005; Pellegrini et al., 2007; Tong et al., 2009). Our data support previous conclusions from studies focusing on the telencephalon (Diotel et al., 2010a, 2010b; März et al., 2010). We showed that radial glial cells co-express both markers in the telencephalon, the diencephalon, and the mes- and metencephalon. However, obvious regional differences were observed between cyp19a1b-GFP and Blbp expression notably in the thalamus, the optic tectum and in cells surrounding the lateral recess (Figs. 3 and 4 ). These differences are not due to transgene leaking as cyp19a1b-GFP transgenic fish line fully recapitulates endogenous AroB as previously reported (Tong et al., 2009 and data not shown), and was partially reported in zebrafish for AroB, Blbp and cxcr4, a chemokine receptor (Diotel et al., 2010b).

Such a radial glia heterogeneity was previously described in mammals and is currently not completely understood (Pinto and Gotz, 2007). This heterogeneity could stem from the distinct neurogenic versus gliogenic properties, proliferation rate (long- term and short-term self-renewing) or also distinct regenerative properties (Barry et al., 2014; Tack et al., 2012).

\subsection{Proliferation is preferentially associated with certain markers according to the niche}

We also looked for a potential difference in AroB or Blbp expression in proliferative radial glial cells. Our results clearly show that Blbp expression is preferentially and significantly more associated with radial glia proliferation in regions displaying strong cyp19a1b-GFP and Blbp co-expression (i.e.: A, Dl, Dm, Vd, Vv, Vs, $\mathrm{PPv})$. There was no preferential expression associated with proliferation in the preoptic area and the Vp, while cyp19a1b-GFP appears to be preferentially associated with proliferation of radial glia in the dorsal zone of the periventricular hypothalamus where the LR starts to open. Significantly more proliferative radial glia express at least cyp19a1b-GFP compared to Blbp (89.9\% Vs. $65.5 \%$; Table 1 and Fig. 5G), suggesting potential differences in the regulation of 
Table 1

Expression and statistical analysis of cypa19a1b-GFP and/or Blbp-positive proliferative radial glial cells in different brain regions.

\begin{tabular}{|c|c|c|c|c|c|c|c|c|c|c|}
\hline \multirow{2}{*}{$\begin{array}{l}\text { Zebrafish } \\
\text { brain atlas } \\
\text { level }\end{array}$} & \multirow{2}{*}{$\begin{array}{l}\text { Brain } \\
\text { regions }\end{array}$} & \multicolumn{3}{|c|}{$\%$ of proliferative radial glia expressing: } & \multicolumn{3}{|l|}{ ANOVA (p-value) } & \multicolumn{3}{|c|}{$\%$ of proliferative radial glia expressing: } \\
\hline & & $\begin{array}{l}\text { Cyp19a1b-GFP } \\
\text { and Blbp }\end{array}$ & $\begin{array}{l}\text { Cyp19a1b-GFP } \\
\text { only }\end{array}$ & Blbp only & $\begin{array}{l}\text { Cyp19a1b-GFP/Blbp } \\
\text { vs. Cyp 19a1b-GFP }\end{array}$ & $\begin{array}{l}\text { Cyp19a1b-GFP/Blbp } \\
\text { vs. Blbp }\end{array}$ & $\begin{array}{l}\text { Cyp19a1b-GFP } \\
\text { vs. Blbp }\end{array}$ & Cyp19a1b-GFP & Blbp & $\begin{array}{l}\text { Student's t-test } \\
\text { Cyp19a1b-GFP vs. } \\
\text { Blbp (p-value) }\end{array}$ \\
\hline 71 & Vv & $66.6( \pm 8.1)$ & $1.2( \pm 0.7)$ & $32.2( \pm 8.5)$ & $<0.0001$ & 0.0038 & 0.0072 & 67.8 & 98.8 & 0.0066 \\
\hline 71 & Vd & $61.2( \pm 7.7)$ & $0.7( \pm 0.7)$ & $38.1( \pm 8.1)$ & $<0.0001$ & 0.0272 & 0.0016 & 61.9 & 99.3 & 0.0018 \\
\hline 92 & Ppa & $92.9( \pm 4.5)$ & $1.4( \pm 1.2)$ & $5.7( \pm 4.4)$ & $<0.0001$ & $<0.0001$ & NS & 94.3 & 98.6 & NS \\
\hline 98 & $\mathrm{PPa}$ & $81.8( \pm 6.88)$ & $5.3( \pm 3.1)$ & $12.94( \pm 4.7)$ & $<0.0001$ & $<0.0001$ & NS & 87.1 & 94.7 & NS \\
\hline 92 & Vs & $79.9( \pm 4)$ & $0( \pm 0)$ & $20.1( \pm 4)$ & $<0.0001$ & $<0.0001$ & 0.0002 & 79.9 & 100.0 & 0.0003 \\
\hline 98 & Vp & $85.4( \pm 5.5)$ & $5.80( \pm 4.3)$ & $8.8( \pm 3.4)$ & $<0.0001$ & $<0.0001$ & NS & 91.2 & 94.2 & NS \\
\hline 114 & Dm & $68.6( \pm 3.5)$ & $1.7( \pm 1.9)$ & $29.7( \pm 3.7)$ & $<0.0001$ & $<0.0001$ & $<0.0001$ & 70.4 & 98.3 & $<0.0001$ \\
\hline 114 & Dl & $55.6( \pm 5.2)$ & $0.92( \pm 0.7)$ & $43.5( \pm 5)$ & $<0.0001$ & 0.0392 & $<0.0001$ & 56.5 & 99.1 & $<0.0001$ \\
\hline $121 / 125$ & PPp & $54.9( \pm 7.2)$ & $14.3( \pm 6.6)$ & $30.8( \pm 8)$ & 0.0007 & 0.0225 & NS & 69.2 & 85.7 & NS \\
\hline 131 & A & $24.9( \pm 6.9)$ & $\mathbf{0}( \pm 0)$ & $75.1( \pm 6.6)$ & 0.0079 & $<0.0001$ & $<0.0001$ & 20.7 & 83.6 & 0.006 \\
\hline 158 & PPv & $8.9( \pm 3.2)$ & $0.7( \pm 0.8)$ & $90.4( \pm 3)$ & 0.0262 & $<0.0001$ & $<0.0001$ & 9.7 & 99.3 & $<0.0001$ \\
\hline 168 & Hd (LR) & $55.4( \pm 3.5)$ & $34.5( \pm 5.5)$ & $10.1( \pm 4.4)$ & 0.0027 & $<0.0001$ & 0.0008 & 89,9 & 65,5 & 0.0035 \\
\hline
\end{tabular}

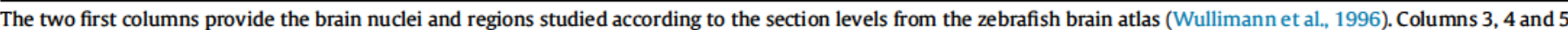

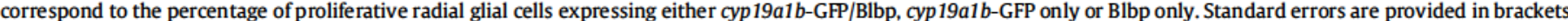

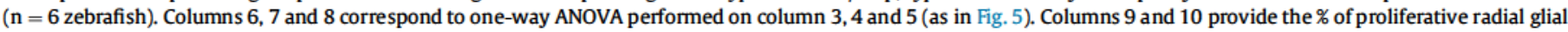

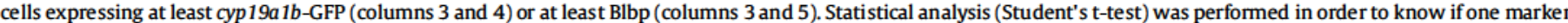

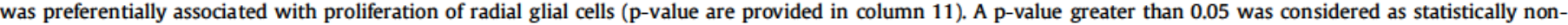
significant (NS)

the neurogenic niche activity. Although one can argue that some radial glial cells could be Blbp and cyp19a1b-GFP double-negative, leading to over-estimation of our measurements, the detailed studies on radial glial cells in zebrafish confirm the consistent coexpression of markers (Baulieu and Schumacher, 2000; Diotel et al., 2010b; Lindsey et al., 2012; März et al., 2010), and such support the conclusion that our quantifications are not overestimated.

\subsection{Blbp, DHA and estrogens: links with neurogenesis}

During embryogenesis in rats, the preferential association of Blbp with proliferative zone is of particular interest as Blbp is downstream of the neurogenic transcription factor Pax6 and enhances cell proliferation (Arai et al., 2005). New reports also suggest an involvement of Blbp in neurogenesis in the SVZ and in the dentate gyrus of rodents (Marko et al., 2011; Matsumata et al., 2012; Schnell et al., 2014; Watanabe et al., 2007). Other data obtained in adult monkeys show an up-regulation of Blbp in the hippocampus of post-ischemic brains compared to controls and suggest that Blbp is part of the molecular machinery regulating the activity of the neurogenic niche by providing fatty acids to progenitor cells (Boneva et al., 2011). Blbp was also reported to be positively involved in proliferation and invasion of human glioblastoma (Chen et al., 2007). Blbp ligand, DHA, is an omega-3 polyunsaturated fatty acid essential for proper brain development and functioning (Crawford et al., 2013; Hoffman et al., 2009; Janssen and Kiliaan, 2014). Mice fed with DHA and other n-3 polyunsaturated fatty acids show better exploratory behavior and spatial memory but display decreased neurogenesis in the hippocampus, while in rats DHA does not affect hippocampal cell proliferation and positively impacts neuronal production and/or survival (Janssen et al., 2015; Tokuda et al., 2014). These data strongly suggest important roles for Blbp and DHA in neurogenesis and behavior that deserve further investigation. Interestingly, several studies suggest a link between hormones, especially estrogens, and DHA levels in the brain. For instance, DHA levels are higher in women than in men, and among women, those taking oral contraceptive pills display higher DHA concentrations (Giltay et al., 2004). Similar sex differences and hormonal influences were also observed in rats and correlated with ovarian hormones (McNamara et al., 2009). Interestingly, the brains of embryonic and adult zebrafish express elovl4a that codes for the fatty acid elongase 4, an enzyme involved in DHA synthesis (Monroig et al., 2010) and suggest that DHA can be locally synthesized from precursors in the brain of fish. This observation needs to be linked to the capacity of the zebrafish brain to synthesize estrogens de novo (Diotel et al., 2011a, 2011b). In the brain, estrogens exert various effects on stem cell and neuronal activities by modulating proliferation of neural progenitors (Brock et al., 2010; Galea, 2008; MartinezCerdeño et al., 2006), neuronal migration and differentiation, brain plasticity (Brinton, 2009; Fan et al., 2006; Murashov et al., 2004; Wang et al., 2003), as well as cell survival (Garcia-Segura, 2008; Hill et al., 2009; Wang et al., 2001). In adult zebrafish, 17 $\beta$ estradiol was shown to regulate brain proliferation, migration and survival (Coumailleau et al., 2015; Diotel et al., 2013; Makantasi and Dermon, 2014; Pellegrini et al., 2015). Given that radial glial cells appear to be targeted by estrogens (Coumailleau et al., 2015; Diotel et al., 2011b; Menuet et al., 2005; Pellegrini et al., 2015, 2013), AroBpositive radial glial cells could affect their own activity as well as that of their neighbors by producing estrogens in an autocrine and/ or paracrine manner. Consequently, it is likely that estrogen, Blbp and its ligand could modulate neurogenesis in a combinatory manner.

Taken together these data suggest key roles for Blbp, and its ligand DHA in stem cell activity and neurogenesis. Further investigations using Blbp vivo-morpholino and over-expression techniques could provide important inside on the roles of Blbp and its ligand in homeostatic and reparative neurogenesis in fish.

\subsection{Conclusions}

To conclude, we provide a detailed mapping of Blbp in the whole brain of adult zebrafish, showing Blbp co-expression with the radial glia marker AroB and radial glial cell heterogeneity. Interestingly, proliferative radial glial cells are preferentially associated with Blbp expression in most brain regions, suggesting key roles for this binding protein and its ligand in stem cell activity and brain functions. Given (1) the continuous growth of Teleost fish during their lifespan, (2) the maintenance of brain embryonic properties in adult fish (Diotel et al., 2010a) and (3) the importance of DHA for brain development, these results identify Blbp and DHA as potential factors mediating some aspects of brain homeostasis and functions during adulthood in zebrafish. 


\section{Experimental procedure}

\subsection{Animals and ethics}

This work was approved by the ethics committee CREEA (Comité Rennais d'Ethique en matière d'Expérimentation Animale). Zebrafish were housed, handled, and sacrificed in accordance with the European Union regulations concerning the protection of experimental animals. Three to six month-old male and female sexually mature wild-type (Danio rerio, AB strain) and cyp19a1bGFP transgenic zebrafish (Tong et al., 2009) were housed in the zebrafish facility of the IFR 140 (INRA SCRIBE, Rennes) and maintained under standard conditions of temperature $\left(28.5^{\circ} \mathrm{C}\right)$ and photoperiod (14-h light/10-h). Fish were anesthetized with Tricaine (MS-222; Sigma-Aldrich; REF: A5040) and sacrificed using an overdose of anesthetic. Next, brains were partially dissected and fixed over night at $4{ }^{\circ} \mathrm{C}$ in $4 \%$ paraformaldehyde (4\% PFA) in saline phosphate buffer (PBS, pH 7.4). The next day, brains were extracted and fixed at $4{ }^{\circ} \mathrm{C}$ in $4 \%$ PFA-PBS, before paraffin embedding.

\subsection{Primary antibodies}

A rabbit polyclonal antibody raised against the $\sim 15 \mathrm{kD}$ rat/mouse Blbp was used (1:2000; Chemicon International Serological Company; REF: AB9558; RRID: AB_2314014). The specificity of this antibody was previously assessed in zebrafish by Western Blotting (Diotel et al., 2010b) and was identified as a marker of radial glial cells.

A mouse monoclonal antibody raised against the PCNA (proliferative cell nuclear antigen) was used for detecting proliferative cells (1:100; Clone PC10; Dako, Glostrup, Denmark; REF: M0879; RRID: AB_2160651). This antibody reacts with proliferating cells in vertebrate species, including zebrafish (März et al., 2010; Pellegrini et al., 2007).

Post-mitotic neurons were identified with a mouse monoclonal antibody raised against the human nuclear protein HuC/D (1:20; Clone 16A11; Molecular Probes, Eugen, OR; REF: A21271; RRID: AB_221448). The specificity of this antibody was tested by the supplier, and the anti-HuC/D was previously used in zebrafish (Pellegrini et al., 2007).

\subsection{Immunohistochemistry}

For Blbp mapping, immunohistochemistry was performed on paraffin brain sections $(6 \mu \mathrm{m})$ prepared with a microtome (Microm HM 355 S). Sections were deparaffinised in xylene, rehydrated through graded ethanol (100-30\%), rinsed twice in PBS ( $\mathrm{pH} 7.4)$ followed by antigen retrieval in sodium citrate buffer $\left(\mathrm{pH} 6 ; 80^{\circ} \mathrm{C}\right)$ for $30 \mathrm{~min}$. Slides were rinsed twice in $0.2 \%$ Triton PBS (PBS-T) and non-specific binding was blocked in PBS-T containing $1 \%$ milk powder for $45 \mathrm{~min}$ at room temperature. Finally, sections were incubated over night at room temperature in a humidified chamber with the appropriate first antibodies diluted in PBS containing $0.5 \%$ milk powder. The next day, the sections were washed several times in PBS-T and incubated with Alexa Fluor ${ }^{\circledR}$ goat anti-rabbit 594 (1:200; Invitrogen Molecular probes, Eugene, OR, REF: A-11037; RRID: AB_10561549) for $1 \mathrm{~h} 30$ at room temperature in a dark and humidified chamber. After three washes in PBS-T, slides were mounted with the antifading medium Vectashield (Vector) containing 4,6-diamino-2-phenylindole (DAPI), to visualize cell nuclei. Blbp mapping was performed on three male and three female adult zebrafish.

For Blbp staining on cyp19a1b-GFP zebrafish line, antigen retrieval was performed in a sodium citrate buffer $\left(\mathrm{pH} 7.1 ; 64{ }^{\circ} \mathrm{C}\right)$ for $1 \mathrm{~h} 15$ in order to preserve GFP fluorescence.
For double Blbp and PCNA immunohistochemistry on cyp19a1bGFP zebrafish line, antigen retrieval was performed in a sodium citrate buffer $\left(\mathrm{pH} 7.1 ; 64{ }^{\circ} \mathrm{C}\right)$ for $1 \mathrm{~h} 15$ and Blbp antibody was detected using a biotinylated goat anti-rabbit IgG (1/1500; Vector's lab, REF: BA-1000; RRID: AB_2313606) and revealed by an AMCAstreptavidin complex (1/500; Vector's lab; REF: SA-5008; RRID:AB_2336103). PCNA antibody was revealed with Alexa fluor ${ }^{\circledR}$ goat anti-mouse 594 (1:200; Invitrogen Molecular probes, Eugene, OR, REF: A-11005; RRID: AB_10561507).

\subsection{Microscopy}

Observations were performed on an epifluorescence microscope Olympus Provis equipped with a DP71 digital camera or with a Zeiss Apotome. Images were saved in "TIFF" format with Analysis software to allow image stacking.

\subsection{Statistical analysis of cyp19a1b-GFP (AroB) and blbp expression in proliferative radial glial cells}

For each brain nucleus or region, identified according the Zebrafish brain Atlas from Wullimann (Wullimann et al., 1996), counting was performed on three successive sections of 6 adult female zebrafish. Counting was performed by two different experimenters who obtained similar data that were averaged. Statistical analysis was performed using ANOVA or Student's t-test. A p-value below 0.05 was considered statistically significant.

\subsection{Nomenclature}

The nomenclature for brain nuclei and regions is according to that established in the zebrafish atlas by Wullimann and colleagues (Wullimann et al., 1996).

Abbreviations of anatomical terms used in this study according to Wullimann atlas [84].

A, anterior thalamic nucleus;

PN, accessory pretectal nucleus;

ATN, anterior tuberal nucleus;

CCe, corpus cerebelli;

Chab, habenular commissure;

Chor, horizontal commissure;

$\mathrm{CM}$, corpus mamillare;

$\mathrm{CP}$, central posterior thalamic nucleus;

$\mathrm{CPN}$, central pretectal nucleus;

Cpop, postoptic commissure;

Cpost, posterior commissure;

$\mathrm{D}$, dorsal telencephalic area;

Dc, central zone of dorsal telencephalic area;

Dd, dorsal zone of dorsal telencephalic area;

DiV, diencephalic ventricle;

$\mathrm{Dl}$, lateral zone of dorsal telencephalic area;

Dm, medial zone of dorsal telencephalic area;

DOT, dorsomedial optic tract;

Dp, posterior zone of dorsal telencephalic area;

DP, dorsal posterior thalamic nucleus;

DTN, dorsal tegmental nucleus;

ECL, external cellular layer of olfactory bulb;

EG, eminentia granularis;

ENv, entopendoncular nucleus, ventral part;

FR, fasciculus retroflexus;

GL, glomerular layer of olfactory bulb;

Had, dorsal habenular nucleus;

Hav, ventral habenular nucleus;

$\mathrm{Hc}$, caudal zone of periventricular hypothalamus; 
Hd, dorsal zone of periventricular hypothalamus;

$\mathrm{Hv}$, ventral zone of periventricular hypothalamus;

ICL, internal cellular layer of olfactory bulb;

IL, inferior lobe;

LH, lateral hypothalamic nucleus;

LLF: lateral longitudinal fascicle;

LR, lateral recess of diencephalic nucleus;

MLF, medial longitudinal fascicle;

NIII, oculomotor nucleus;

NMLF, nucleus of medial longitudinal fascicle;

NLV, nucleus lateralis valvulae;

PG, preglomerular nucleus;

PGa, anterior preglomerular nucleus;

PGl, lateral preglomerular nucleus;

Pit, pituitary;

PO, posterior pretectal nucleus;

$\mathrm{PPa}$, parvocellular preoptic nucleus, anterior part;

PPp, parvocellular preoptic nucleus, posterior part;

$\mathrm{PR}$, posterior recess of diencephalic ventricle;

PSp, parvocellular superficial pretectal nucleus;

PTN, posterior tuberal nucleus;

$\mathrm{PPv}$, periventricular pretectal nucleus;

$\mathrm{R}$, rostrolateral nucleus;

$\mathrm{RF}$, reticular formation;

$\mathrm{RV}$ : rhombencephalic ventricle;

SC, suprachiasmatic nucleus;

SO, secondary octaval population;

$\mathrm{TeO}$, tectum opticum;

$\mathrm{TL}$, torus longitudinalis;

TLa, torus lateralis;

TPp, periventricular nucleus of posterior tuberculum;

TS, torus semicircularis;

$\mathrm{V}$, ventral telencephalic area;

V3, third ventricle;

VII, sensory root of the facial nerve;

VIII, octaval nerve;

VCe, valvula cerebelli;

$\mathrm{Vd}$, dorsal nucleus of ventral telencephalic area;

VL, ventrolateral thalamic nucleus;

VM, ventromedial thalamic nucleus;

VOT, ventrolateral optic tract;

$\mathrm{Vp}$, postcommissural nucleus of ventral telencephalic area;

$\mathrm{Vv}$, ventral nucleus of dorsal telencephalic area;

ZL, zona limitans.

\section{Conflicts of interest}

None of the authors have any competing interests.

\section{Authors' contributions}

$\mathrm{OK}, \mathrm{CV}$ and EP designed the experiments and supervised the work. ND and CV conducted the experiments. ND, CV, OK and EP analyzed the data and wrote the manuscript. All authors read and approved the final manuscript.

\section{Acknowledgments}

The Post-Grenelle grant NEMO (to François Brion and Olivier Kah) and a NSC Taiwan-CNRS France exchange program (to BonChu Chung and Olivier Kah) supported this research. The outstanding assistance of the staff of the BIOSIT zebrafish facility (INRA, Laboratoire de Physiologie et Génomique des Poissons) was greatly appreciated. We thank Dr. Marie-Lise Thieulant for her advice during this work, Sara Powers and Pr. Thierry Charlier for proofreading the manuscript.

\section{References}

Adolf, B., Chapouton, P., Lam, C.S., Topp, S., Tannhauser, B., Strähle, U., Götz, M. Bally-Cuif, L, 2006. Conserved and acquired features of adult neurogenesis in the zebrafish telencephalon. Dev. Biol. 295, 278-293.

Anthony, T.E., Mason, H.A., Gridley, T., Fishell, G., Heintz, N., 2005. Brain lipidbinding protein is a direct target of Notch signaling in radial glial cells. Genes Dev. 19, 1028-1033.

Arai, Y., Funatsu, N., Numayama-Tsuruta, K., Nomura, T., Nakamura, S., Osumi, N., 2005. Role of Fabp7, a downstream gene of Pax6, in the maintenance of neuroepithelial cells during early embryonic development of the rat cortex. J. Neurosci. Off. J. Soc. Neurosci. 25, 9752-9761.

Barry, D.S., Pakan, J.M., McDermott, K.W., 2014. Radial glial cells: key organisers in CNS development. Int. J. Biochem. Cell Biol. 46, 76-79.

Baulieu, E., Schumacher, M., 2000. Progesterone as a neuroactive neurosteroid, with special reference to the effect of progesterone on myelination. Steroids 65 , 605-612.

Bentivoglio, M., Mazzarello, P., 1999. The history of radial glia. Brain Res. Bull. 49 305-315.

Boneva, N.B., Kaplamadzhiev, D.B., Sahara, S., Kikuchi, H., Pyko, I.V., Kikuchi, M., Tonchev, A.B., Yamashima, T., 2011. Expression of fatty acid-binding proteins in adult hippocampal neurogenic niche of postischemic monkeys. Hippocampus 21, 162-171.

Brinton, R.D., 2009. Estrogen-induced plasticity from cells to circuits: predictions for cognitive function. Trends Pharmacol. Sci. 30, 212-222.

Brock, O., Keller, M., Veyrac, A., Douhard, Q., Bakker, J., 2010. Short term treatment with estradiol decreases the rate of newly generated cells in the subventricular zone and main olfactory bulb of adult female mice. Neuroscience 166, 368-376.

Chen, C.J., Kono, H., Golenbock, D., Reed, G., Akira, S., Rock, K.L., 2007. Identification of a key pathway required for the sterile inflammatory response triggered by dying cells. Nat. Med. 13, 851-856.

Cole, G.M., Ma, Q.L., Frautschy, S.A., 2010. Dietary fatty acids and the aging brain Nutr. Rev. 68 (Suppl. 2), S102-S111.

Coumailleau, P., Pellegrini, E., Adrio, F., Diotel, N., Cano-Nicolau, J., Nasri, A, Vaillant, C., Kah, O., 2015. Aromatase, estrogen receptors and brain development in fish and amphibians. Biochim. Biophys. Acta 1849, 152-162.

Crawford, M.A., Broadhurst, C.L., Guest, M., Nagar, A., Wang, Y., Ghebremeskel, K. Schmidt, W.F., 2013. A quantum theory for the irreplaceable role of docosahexaenoic acid in neural cell signalling throughout evolution. Prostagl. Leukot. Essent. Fat. Acids 88, 5-13.

D'Amico, L.A., Boujard, D., Coumailleau, P., 2011. Proliferation, migration and differentiation in juvenile and adult Xenopus laevis brains. Brain Res. 1405, 31-48.

Dinarello, C.A., 2012. Keep up the heat on IL-1. Blood 120, 2538-2539.

Diotel, N., Do Rego, J.L., Anglade, I., Vaillant, C., Pellegrini, E., Gueguen, M.M., Mironov, S., Vaudry, H., Kah, O., 2011a. Activity and expression of steroidogenic enzymes in the brain of adult zebrafish. Eur. J. Neurosci. 34, 45-56.

Diotel, N., Do Rego, J.L., Anglade, I., Vaillant, C., Pellegrini, E., Vaudry, H., Kah, O. 2011b. The brain of teleost fish, a source, and a target of sexual steroids. Front. Neurosci. 5, 137.

Diotel, N., Le Page, Y., Mouriec, K., Tong, S.K., Pellegrini, E, Vaillant, C., Anglade, I., Brion, F., Pakdel, F., Chung, B.C., Kah, O., 2010a. Aromatase in the brain of teleost fish: expression, regulation and putative functions. Front. Neuroendocrinol. 31 $172-192$

Diotel, N., Rodriguez Viales, R., Armant, O., Marz, M., Ferg, M., Rastegar, S. Strahle, U., 2015. Comprehensive expression map of transcription regulators in the adult zebrafish telencephalon reveals distinct neurogenic niches. J. Comp. Neurol. 523, 1202-1221.

Diotel, N., Vaillant, C., Gabbero, C., Mironov, S., Fostier, A., Gueguen, M.M. Anglade, I., Kah, O., Pellegrini, E., 2013. Effects of estradiol in adult neurogenesis and brain repair in zebrafish. Horm. Behav. 63, 193-207.

Diotel, N., Vaillant, C., Gueguen, M.M., Mironov, S., Anglade, I., Servili, A., Pellegrini, E., Kah, O., 2010b. Cxcr4 and Cxcl12 expression in radial glial cells of the brain of adult zebrafish. J. Comp. Neurol. 518, 4855-4876.

Edelmann, K., Glashauser, L, Sprungala, S., Hesl, B., Fritschle, M., Ninkovic, J., Godinho, L., Chapouton, P., 2013. Increased radial glia quiescence, decreased reactivation upon injury and unaltered neuroblast behavior underlie decreased neurogenesis in the aging zebrafish telencephalon. J. Comp. Neurol. 521, 3099-3115.

Fan, X., Warner, M., Gustafsson, J.A., 2006. Estrogen receptor beta expression in the embryonic brain regulates development of calretinin-immunoreactive GABAergic interneurons. Proc. Natl. Acad. Sci. U. S. A. 103, 19338-19343.

Feng, L., Hatten, M.E., Heintz, N., 1994. Brain lipid-binding protein (BLBP): a novel signaling system in the developing mammalian CNS. Neuron 12, 895-908.

Feng, L., Heintz, N., 1995. Differentiating neurons activate transcription of the brain lipid-binding protein gene in radial glia through a novel regulatory element. Development 121, 1719-1730.

Forlano, P.M., Deitcher, D.L., Myers, D.A., Bass, A.H., 2001. Anatomical distribution and cellular basis for high levels of aromatase activity in the brain of teleost fish: aromatase enzyme and mRNA expression identify glia as source. J. Neurosci. Off. J. Soc. Neurosci. 21, 8943-8955.

Galea, L.A., 2008. Gonadal hormone modulation of neurogenesis in the dentate gyrus of adult male and female rodents. Brain Res. Rev. 57, 332-341. 
Galea, L.A., Spritzer, M.D., Barker, J.M., Pawluski, J.L., 2006. Gonadal hormone modulation of hippocampal neurogenesis in the adult. Hippocampus 16, $225-232$.

Galea, L.A., Uban, K.A., Epp, J.R., Brummelte, S., Barha, C.K., Wilson, W.L., Lieblich, S.E., Pawluski, J.L., 2008. Endocrine regulation of cognition and neuroplasticity: our pursuit to unveil the complex interaction between hormones, the brain, and behaviour. Can. J. Exp. Psychol. 62, 247-260.

Garcia-Segura, L.M., 2008. Aromatase in the brain: not just for reproduction anymore. J. Neuroendocrinol, 20, 705-712.

Garcia-Segura, L.M., Wozniak, A., Azcoitia, I., Rodriguez, J.R., Hutchison, R.E., Hutchison, J.B., 1999. Aromatase expression by astrocytes after brain injury: implications for local estrogen formation in brain repair. Neuroscience 89 , 567-578.

Giltay, E.J., Gooren, LJ., Toorians, A.W., Katan, M.B., Zock, P.L., 2004. Docosahexaenoic acid concentrations are higher in women than in men because of estrogenic effects. Am. J. Clin. Nutr. 80, 1167-1174.

Glasauer, S.M., Neuhauss, S.C., 2014. Whole-genome duplication in teleost fishes and its evolutionary consequences. Mol. Genet. Genom. MGG 289, 1045-1060.

Goncalves, D., Teles, M., Alpedrinha, J., Oliveira, R.F., 2008. Brain and gonadal aromatase activity and steroid hormone levels in female and polymorphic males of the peacock blenny Salaria pavo. Horm. Behav. 54, 717-725.

Gronert, K., 2008. Lipid autacoids in inflammation and injury responses: a matter of privilege. Mol. Interv. $8,28-35$.

Hartfuss, E., Galli, R., Heins, N., Gotz, M., 2001. Characterization of CNS precursor subtypes and radial glia. Dev. Biol. 229, 15-30.

Hebsgaard, J.B., Nelander, J., Sabelstrom, H., Jonsson, M.E., Stott, S., Parmar, M., 2009. Dopamine neuron precursors within the developing human mesencephalon show radial glial characteristics. Glia 57, 1648-1658.

Hill, R.A., Chua, H.K., Jones, M.E., Simpson, E.R., Boon, W.C., 2009. Estrogen deficiency results in apoptosis in the frontal cortex of adult female aromatase knockout mice. Mol. Cell. Neurosci. 41, 1-7.

Hoffman, D.R., Boettcher, J.A., Diersen-Schade, D.A., 2009. Toward optimizing vision and cognition in term infants by dietary docosahexaenoic and arachidonic acid supplementation: a review of randomized controlled trials. Prostagl. Leukot. Essent. Fat. Acids 81, 151-158.

Hsieh, J., 2012. Orchestrating transcriptional control of adult neurogenesis. Genes Dev. 26, 1010-1021.

Ito, Y., Tanaka, H., Okamoto, H., Ohshima, T., 2010. Characterization of neural stem cells and their progeny in the adult zebrafish optic tectum. Dev. Biol. 342, $26-38$.

Janssen, C.I., Kiliaan, A.J., 2014. Long-chain polyunsaturated fatty acids (LCPUFA) from genesis to senescence: the influence of LCPUFA on neural development, aging, and neurodegeneration. Prog. Lipid Res. 53, 1-17.

Janssen, C.I., Zerbi, V., Mutsaers, M.P., de Jong, B.S., Wiesmann, M., Arnoldussen, I.A., Geenen, B., Heerschap, A., Muskiet, F.A., Jouni, Z.E., van Tol, E.A., Gross, G. Homberg, J.R., Berg, B.M., Kiliaan, A.J., 2015. Impact of dietary n-3 polyunsaturated fatty acids on cognition, motor skills and hippocampal neurogenesis in developing C57BL/6J mice. J. Nutr. Biochem. 26, 24-35.

Kah, O., Pellegrini, E, Mouriec, K., Diotel, N., Anglade, I., Vaillant, C., Thieulant, M.L. Tong, S.K., Brion, F., Chung, B.C., Pakdel, F., 2009. Oestrogens and neurogenesis: new functions for an old hormone. Lessons from the zebrafish. J. Soc. Biol. 203, 29-38.

Kaslin, J., Ganz, J., Geffarth, M., Grandel, H., Hans, S., Brand, M., 2009. Stem cells in the adult zebrafish cerebellum: initiation and maintenance of a novel stem cell niche. J. Neurosci. Off. J. Soc. Neurosci. 29, 6142-6153.

Krelin, Y., Voronov, E., Dotan, S., Elkabets, M., Reich, E, Fogel, M., Huszar, M. Iwakura, Y., Segal, S., Dinarello, C.A., Apte, R.N., 2007. Interleukin-1beta-driven inflammation promotes the development and invasiveness of chemical carcinogen-induced tumors. Cancer Res. 67, 1062-1071.

Kurtz, A., Zimmer, A., Schnutgen, F., Bruning, G., Spener, F., Muller, T., 1994. The expression pattern of a novel gene encoding brain-fatty acid binding protein correlates with neuronal and glial cell development. Development 120 , 2637-2649.

Lassiter, C.S., Linney, E, 2007. Embryonic expression and steroid regulation of brain aromatase cyp19a1b in zebrafish (Danio rerio). Zebrafish 4, 49-57.

Li, H., Jin, G., Qin, J., Yang, W., Tian, M., Tan, X., Zhang, X., Shi, J., Zou, L., 2011. Identification of neonatal rat hippocampal radial glia cells in vitro. Neurosci. Lett. 490, 209-214.

Lind sey, B.W., Darabie, A., Tropepe, V., 2012. The cellular composition of neurogenic periventricular zones in the adult zebrafish forebrain. J. Comp. Neurol. 520, 2275-2316.

Liu, R.Z, Denovan-Wright, E.M., Degrave, A., Thisse, C. Thisse, B, Wright, J.M., 2004 Differential expression of duplicated genes for brain-type fatty acid-binding proteins (fabp7a and fabp7b) during early development of the CNS in zebrafish (Danio rerio). Gene Expr. Patterns 4, 379-387.

Liu, R.Z, Denovan-Wright, E.M., Wright, J.M., 2003. Structure, mRNA expression and linkage mapping of the brain-type fatty acid-binding protein gene (FABP7) from zebrafish (Danio rerio). Eur. J. Biochem. FEBS 270, 715-725.

Makantasi, P., Dermon, C.R., 2014. Estradiol treatment decreases cell proliferation in the neurogenic zones of adult female zebrafish (Danio rerio) brain. Neuroscience $277,306-320$.

Marko, K., Kohidi, T., Hadinger, N., Jelitai, M., Mezo, G., Madarasz, E., 2011. Isolation of radial glia-like neural stem cells from fetal and adult mouse forebrain via selective adhesion to a novel adhesive peptide-conjugate. PLoS One 6, e28538.

Martinez-Cerdeño, V., Noctor, S.C., Kriegstein, A.R., 2006. Estradiol stimulates progenitor cell division in the ventricular and subventricular zones of the embryonic neocortex. Eur. J. Neurosci. 24, 3475-3488.

März, M., Chapouton, P., Diotel, N., Vaillant, C., Hesl, B., Takamiya, M., Lam, C.S. Kah, O., Bally-Cuif, L, Strähle, U., 2010. Heterogeneity in progenitor cell subtypes in the ventricular zone of the zebrafish adult telencephalon. Glia 58, 870-888.

Matsumata, M., Sakayori, N., Maekawa, M., Owada, Y., Yoshikawa, T., Osumi, N., 2012. The effects of Fabp7 and Fabp 5 on postnatal hippocampal neurogenesis in the mouse. Stem Cells 30, 1532-1543.

McNamara, R.K., Able, J., Jandacek, R., Rider, T., Tso, P., 2009. Gender differences in rat erythrocyte and brain docosahexaenoic acid composition: role of ovarian hormones and dietary omega-3 fatty acid composition. Psychoneuroendocrinology 34, 532-539.

Menuet, A., Pellegrini, E, Brion, F., Gueguen, M.M., Anglade, I., Pakdel, F., Kah, O., 2005. Expression and estrogen-dependent regulation of the zebrafish brain aromatase gene. J. Comp. Neurol. 485, 304-320.

Monroig, O., Rotllant, J., Cerda-Reverter, J.M., Dick, J.R., Figueras, A., Tocher, D.R., 2010. Expression and role of Elovl4 elongases in biosynthesis of very long-chain fatty acids during zebrafish Danio rerio early embryonic development. Biochim. Biophys. Acta 1801, 1145-1154.

Mouriec, K., Lareyre, J.J., Tong, S.K., Le Page, Y., Vaillant, C., Pellegrini, E, Pakdel, F., Chung, B.C., Kah, O., Anglade, I., 2009 Oct. Early regulation of brain aromatase (cyp19a1b) by estrogen receptors during zebrafish development. Dev. Dyn. 238 (10), 2641-2651. http://dx.doi.org/10.1002/dvdy.22069. PMID: 19718764.

Mouriec, K., Pellegrini, E., Anglade, I., Menuet, A., Adrio, F., Thieulant, M.L., Pakdel, F., Kah, 0., 2008. Synthesis of estrogens in progenitor cells of adult fish brain: evolutive novelty or exaggeration of a more general mechanism implicating estrogens in neurogenesis? Brain Res. Bull. 75, 274-280.

Murashov, A.K., Pak, E.S., Hendricks, W.A., Tatko, L.M., 2004. 17beta-Estradiol enhances neuronal differentiation of mouse embryonic stem cells. FEBS Lett. 569, 165-168.

Murrell, W., Feron, F., Wetzig, A., Cameron, N., Splatt, K., Bellette, B., Bianco, J., Perry, C., Lee, G., Mackay-Sim, A., 2005. Multipotent stem cells from adult olfactory mucosa. Dev, Dyn. 233, 496-515.

Owada, Y., Abdelwahab, S.A., Kitanaka, N., Sakagami, H., Takano, H., Sugitani, Y., Sugawara, M., Kawashima, H., Kiso, Y., Mobarakeh, J.I., Yanai, K., Kaneko, K., Sasaki, H., Kato, H., Saino-Saito, S., Matsumoto, N., Akaike, N., Noda, T., Kondo, H., 2006. Altered emotional behavioral responses in mice lacking braintype fatty acid-binding protein gene. Eur. J. Neurosci. 24, 175-187.

Pasmanik, M., Callard, G.V., 1985. Aromatase and 5 alpha-reductase in the teleost brain, spinal cord, and pituitary gland. Gen. Comp. Endocrinol. 60, 244-251.

Pellegrini, E., Coumailleau, P., Kah, O., Diotel, N., 2015. Aromatase and estrogens: involvement in constitutive and regenerative neurogenesis in adult zebrafish. In: Duncan Kelli, A. (Ed.), Estrogen Effects on Traumatic Brain Injury - Mechanisms of Neuroprotection and Repair.

Pellegrini, E, Menuet, A., Lethimonier, C., Adrio, F., Gueguen, M.M., Tascon, C., Anglade, I., Pakdel, F., Kah, 0., 2005. Relationships between aromatase and estrogen receptors in the brain of teleost fish. Gen. Comp. Endocrinol. 142, 60-66.

Pellegrini, E, Mouriec, K., Anglade, I., Menuet, A., Le Page, Y., Gueguen, M.M., Marmignon, M.H., Brion, F. Pakdel, F., Kah, O, 2007. Identification of aromatasepositive radial glial cells as progenitor cells in the ventricular layer of the forebrain in zebrafish. J. Comp. Neurol. 501, 150-167.

Pellegrini, E., Vaillant, C., Diotel, N., Benquet, P., Brion, F., Kah, O., 2013. Expression, regulation and potential functions of aromatase in radial glial cells of the fish brain. In: Balthazart, J. Ball, Gregory, F. (Eds.), Brain Aromatase, Estrogens, and Behavior. Oxford, University Press, Oxford; New York.

Pinto, L., Gotz, M., 2007. Radial glial cell heterogeneity-the source of diverse progeny in the CNS. Prog. Neurobiol, 83, 2-23.

Podgornyi, O.V., Aleksandrova, M.A., 2009. BLBP-immunoreactive cells in the primary culture of neural precursors from embryonic mouse brain. Bull. Exp. Biol. Med. 147, 125-131.

Rakic, P., 1978. Neuronal migration and contact guidance in the primate telencephalon. Postgrad. Med. J. 54 (Suppl. 1), 25-40.

Rodriguez Viales, R., Diotel, N., Ferg, M., Armant, O., Eich, J., Alunni, A., März, M. Bally-Cuif, L., Rastegar, S., Strähle, U., 2015. The helix-loop-helix protein id 1 controls stem cell proliferation during regenerative neurogenesis in the adult zebrafish telencephalon. Stem Cells 33, 892-903.

Rousselot, P., Heintz, N., Nottebohm, F., 1997. Expression of brain lipid binding protein in the brain of the adult canary and its implications for adult neurogenesis. J. Comp. Neurol. 385, 415-426.

Schnell, A., Chappuis, S, Schmutz, I, Brai, E, Ripperger, JA., Schaad, O., Welzl, H. Descombes, P., Alberi, L., Albrecht, U., 2014. The nuclear receptor REV-ERBalpha regulates Fabp7 and modulates adult hippocampal neurogenesis. PloS One 9, e99883.

Simpson, E.R., Mahendroo, M.S., Means, G.D., Kilgore, M.W., Hinshelwood, M.M. Graham-Lorence, S., Amarneh, B., Ito, Y., Fisher, C.R., Michael, M.D., et al., 1994. Aromatase cytochrome P450, the enzyme responsible for estrogen biosynthesis. Endocr. Rev, 15, 342-355.

Steiner, B., Klempin, F., Wang, L., Kott, M., Kettenmann, H., Kempermann, G., 2006. Type-2 cells as link between glial and neuronal lineage in adult hippocampal neurogenesis. Glia 54, 805-814.

Steinke, D., Hoegg, S., Brinkmann, H., Meyer, A., 2006. Three rounds (1R/2R/3R) of genome duplications and the evolution of the glycolytic pathway in vertebrates. BMC Biol. 4, 16. 
Tack, C.J., Stienstra, R., Joosten, L.A., Netea, M.G., 2012. Inflammation links excess fat to insulin resistance: the role of the interleukin-1 family. Immunol. Rev. 249, 239-252.

Takahashi, K., Yamanaka, S., 2006. Induction of pluripotent stem cells from mouse embryonic and adult fibroblast cultures by defined factors. Cell 126, 663-676.

Timmers, R.J., Lambert, J.G., Peute, J., Vullings, H.G., van Oordt, P.G., 1987. Localization of aromatase in the brain of the male African catfish, Clarias gariepinus (Burchell), by microdissection and biochemical identification. J. Comp. Neurol. $258,368-377$.

Tokuda, H., Kontani, M., Kawashima, H., Kiso, Y., Shibata, H., Osumi, N., 2014. Differential effect of arachidonic acid and docosahexaenoic acid on age-related decreases in hippocampal neurogenesis. Neurosci. Res. 88, 58-66.

Tong, S.K., Mouriec, K., Kuo, M.W., Pellegrini, E., Gueguen, M.M., Brion, F., Kah, O. Chung, B.C., 2009. A cyp19a1b-gfp (aromatase B) transgenic zebrafish line that expresses GFP in radial glial cells. Genesis $47,67-73$.
Wang, L, Andersson, S., Warner, M., Gustafsson, J.A., 2001. Morphological abnormalities in the brains of estrogen receptor beta knockout mice. Proc. Natl. Acad. Sci. U. S. A. 98, 2792-2796.

Wang, L., Andersson, S., Warner, M., Gustafsson, J.A., 2003. Estrogen receptor (ER) beta knockout mice reveal a role for ERbeta in migration of cortical neurons in the developing brain. Proc. Natl. Acad. Sci. U. S. A. 100, 703-708.

Watanabe, A., Toyota, T., Owada, Y., Hayashi, T., Iwayama, Y., Matsumata, M. Ishitsuka, Y., Nakaya, A., Maekawa, M., Ohnishi, T., Arai, R., Sakurai, K. Yamada, K., Kondo, H., Hashimoto, K., Osumi, N., Yoshikawa, T., 2007. Fabp7 maps to a quantitative trait locus for a schizophrenia endophenotype. PLoS Biol 5, e297.

Wullimann, M.F., Rupp, B., Reichert, H., 1996. Neuroanatomy of the Zebrafish Brain A Topological Atlas. Birhaüser Verlag, Basel, Switzerland, pp. 1-144.

Xu, L.Z., Sanchez, R., Sali, A., Heintz, N., 1996. Ligand specificity of brain lipidbinding protein. J. Biol. Chem. 271, 24711-24719. 